\title{
Gastrointestinal semptomlara göre kapsül endoskopinin açklayıcı gücü ve önemi
}

\author{
Explanatory power and importance of capsule endoscopy according to gastrointestinal symptoms
}

\section{Süleyman ORMAN ${ }^{1}$, Orhan Sami GÜLTEKIN²}

${ }^{1}$ Istanbul Medeniyet Üniversitesi Göztepe Eğitim Araştırma Hastanesi, Gastroenteroloji Cerrahisi Kliniği, Istanbul

${ }^{2}$ Istanbul Gastroenteroloji Merkezi, Istanbul

Giriş ve Amaç: Kapsül endoskopi sebebi bulunamayan gastrointestinal semptomları araştırmada sıklıkla kullanılan bir tanı yöntemidir. Amacımız gastrointestinal semptomlara göre kapsül endoskopinin açıklayıcı gücü ve önemini saptamaktır. Gereç ve Yöntem: Kapsül endoskopi yapılan 95 hasta retrospektif olarak değerlendirildi. Hastaların demografik verileri, şikayetleri, kapsül endoskopik verileri, gastroskopi ve kolonoskopi sonuçları değerlendirildi. Bulgular: Hastalarn \%38,9'u (n=37) kadın; \%61,1'i (n=58) erkek idi. Işlemler sırasında toplam 141 lezyon saptandı. Olguların yaş ortalaması 56,98 18,95 (14-92) idi. Gizli gastrointestinal sistem kanaması ile başvuran hastalarda 44 lezyon saptanmış olup bunların \%61,4'ü jejunumda idi. Açık gastrointestinal sistem kanaması ile başvuran hastalarda 56 lezyon saptanmış olup bunların \%42,9'u jejunumda idi. Ishal ile başvuran hastalarda 16 lezyon saptanmıs olup bunların \%50'si ileumda yer almaktaydı. Karın ağrısı ile başvuran hastalarda 25 lezyon saptanmıs olup bunların \%56'sı ileumda görülmekte idi. Açık ve gizli gastrointestinal sistem kanaması şikayetleri bulunan hastalarda en sık saptanan lezyon türü ve yeri jejunal angiodisplaziler olup sirasıly 21/37 ve 20/32 olarak saptand1. Ishal ve karın ağrisı şikayetler bulunan hastalarda en sik saptanan lezyon türü ve yeri ileal Crohn hastalığı olup sirasiyla 4/5 ve 3/4 olarak saptandı. Semptom sayısina göre hastalar değerlendirildiğinde hastaların \%41. I'inde $(n=39)$ yalnızca tek semptom olduğu gözlendi. Semptomlar tek tek ele alındığında hastaların en sik anemi (49/170) ile bassvurduğu gözlenmiştir. Anemi ile başvuran hastalarnn \% 79,6'sında herhangi bir lezyon saptanmıştır. Ancak herhangi bir lezyon saptananların \%97,4'ünün patolojiyi açıklayıcı lezyon olduğu gözlenmiştir. Sonuç: Kapsül endoskopi uygun endikasyonla kullanıldığında gastrointestinal semptomların nedenini saptamada oldukça etkin bir tanı yöntemidir.

Anahtar kelimeler: Kapsül endoskopi, gastroskopi, kolonoskopi
Background and Aims: Capsule endoscopy is a commonly used diagnostic method for investigating gastrointestinal complaints that are not detected by endoscopy. Our aim is to determine the explanatory power and importance of capsule endoscopy according to the type of gastrointestinal symptoms. Materials and Methods: A total of 95 patients who underwent capsule endoscopy were retrospectively evaluated. Demographic data, complaints, capsule endoscopic data, gastroscopy, and colonoscopy results were evaluated. Results: Of the total patients, 38.9\% ( $n=37)$ were female and $61.1 \%(n=58)$ were male. A total of 141 lesions were detected during the procedures. The mean age of the cases was $56.98 \pm 18.95$ (range: 14-92). Forty-four lesions were detected in patients with obscure gastrointestinal bleeding, of which $61.4 \%$ were found in the jejunum. In the patients with overt gastrointestinal bleeding, 56 lesions were found, of which $42.9 \%$ were in the jejunum. Sixteen lesions were found in patients with diarrhea, and $50 \%$ of them were in the ileum. Twenty-five lesions were found in patients with abdominal pain, and $56 \%$ of them were in the ileum. Jejunal angiodysplasia was the most common lesion type and location in patients with overt and occult gastrointestinal bleeding complaints, 21/37 and 20/32, respectively. Patients with diarrhea and abdominal pain had the most common type and location of ileal Crohn's disease, 4/5 and 3/4, respectively. According to the number of symptoms, $41.1 \%(n=39)$ of patients had only one symptom upon evaluation. Examination of individual symptoms revealed that patients were most frequently referred with anemia (49/170). In all, $79.6 \%$ of patients with anemia had lesions; however, $97.4 \%$ of these lesions were elucidatory. Conclusion: Capsule endoscopy is a very effective diagnostic method when it is used with appropriate indications to determine the origin of gastrointestinal symptoms.

Key words: Capsule endoscopy, gastroscopy, colonoscopy

\section{GİRİs}

Günümüzde kapsül endoskopi (KE) ince barsak değerlendirilmesinde tercih edilen ilk tanı yöntemidir (1). Kapsül endoskopi uygulamaya girmeden önce ince barsak ulaşılamaz veya değerlendirilmesi zor kabul edilirdi. Seçilmiş hastalarda anestezi altında enteroskopi yapılırdı (2). Nedeni belirsiz gastrointestinal sistem (GIS) kanamalarında kullanımı kabul edildiğinden beri doğruluğu, güvenilirliği ve invaziv olmaması nedeniyle klinikte kendine geniş bir kullanım alanı bulmuştur (3). Günümüz endikasyonları arasında kaynağı belirsiz demir eksikliği anemisi (DEA), Crohn hastalığı (CH), çölyak hastalığı, ince barsak tümörleri ve kalıtsal polipozis sendromları bulunmaktadır (4). Ancak gerek benzersiz avantajları gerek teknolojideki hızlı gelişmeler ile beraber geleneksel endoskopi ile ulaşlabilen alanlar da dahil, yetersiz veya eksik kalınan kronik ishal, sebebi belirsiz karın ağrısı, bağırsağın motor hastalıkları gibi durumlarda da kullanılabilmektedir (5-8). Alt ve üst endoskopi negatif hastalarda da KE ile gözden kaçan lezyonların saptanabildiği bildirilmiştir $(9,10)$. Çalışmadaki amacımız gastrointestinal semptomlara göre kapsül endoskopinin açıklayıcı gücü ve önemini saptamaktır. 


\section{GEREÇ ve YÖNTEM}

Çalışmamız İstanbul Medeniyet Üniversitesi Göztepe Eğitim ve Araştırma Hastanesi etik kurulunda (2017/0210) numaralı kararı ile kabul edildi. İstanbul Medeniyet Üniversitesi Göztepe Eğitim ve Araştırma Hastanesi Gastroenteroloji Cerrahisi kliniği ve İstanbul Gastroenteroloji Merkezi'ne Ağustos 2011-Ağustos 2017 tarihleri arasında gastrointestinal şikayetleri nedeniyle başvuran ve gastroskopi, kolonoskopi ile tanı konulamaması üzerine kapsül endoskopi yapılan 95 hasta retrospektif olarak değerlendirildi. Hastaların demografik verileri, şikayetleri, kapsül endoskopik verileri, gastroskopi ve kolonoskopi sonuçları değerlendirildi. Çalışmamızda ince barsak kapsülü sistemi olan PillCamTM İB kapsül sistemi (Medtronic, Minneapolis, ABD) kullanıldı. Barsak temizliği için hastalara işlemden iki gün öncesinde posasız sıvı gıdaya başlandı. İşlemden önceki gün iki adet dibazik sodyum fosfat+monobazik sodyum fosfat soda yapilması suretiyle barsak temizliği sağlandı. İşlem saatinden 6 saat öncesine kadar hastaların bol şekilde su alımına izin verildi. Çalışma iki merkezdeki doktor tarafindan farklı hastalara uygulanan kapsül endoskopilerden oluşmakta olup bu iki merkezdeki gastroenterolog ve gastroenterolojik cerrah tarafından kapsül endoskopi değerlendirmeleri yapıldı. Hastaların tümünde kolona ulaşılabildi ve çıkan kolon izlendikten sonra işlem takibi sonlandırıldı. Kolona ulaşılamamış, eksik kalan, kapsül nedeniyle obstrüksiyon gelişen veya hastaların tolere etmediği işlemler bu çalışmaya dahil edilmemiştir.

\section{İstatiksel Analiz}

Çalışmada elde edilen bulgular değerlendirilirken, istatistiksel analizler için NCSS (Number Cruncher Statistical System) 2007 Statistical Software (NCSS LLC, Kaysville, Utah, USA) programı kullanıldı. Çalışma verileri değerlendirilirken tanımlayıcı istatistiksel metodlar olan ortalama, standart sapma, medyan, sıklık ve oran gibi değerler kullanıldı.

\section{BULGULAR}

Istanbul Medeniyet Üniversitesi Göztepe Eğitim ve Araştırma Hastanesi Gastroenteroloji Cerrahisi Kliniği ve İstanbul Gastroenteroloji Merkezi'ne Ağustos 2011- Ağustos 2017 tarihleri arasında çeşitli gastrointestinal semptomlar ile başvuran 95 olguya uygulanan kapsül endoskopi sonuçları incelendi. Olguların yaşları 14 ile 92 yaş arasında değişmekte olup ortalaması $56,98 \pm 18,95$ idi. Olgularm \%38,9'u (n=37) kadın; \%61,1’i $(\mathrm{n}=58)$ erkek idi. 95 hastada var olan semptomların sayısı sırasıla; anemi $(n=49)$, melena $(n=32)$, karın ağrısı $(n=27)$, ishal $(n=17)$, hematokezya $(n=11)$, şişkinlik $(n=8)$, geçirilmiş operasyon ( $n=8)$, dispepsi $(n=4)$, kilo kaybı $(n=3)$, hematemez $(n=3)$, ileus $(n=3)$, bulantı-kusma $(n=2)$, perianal fistül $(n=1)$, kabızlık ( $n=1)$, gaitada gizli kan $(n=1)$ olmak üzere toplamda 170 tane semptom olduğu gözlendi. Hastaların 39'unda tek semptom, 42'sinde iki semptom, 10'unda üç semptom, 3'ünde dört semptom, l'inde ise beş semptom birden mevcuttu (Tablo 1). Hastalarda toplam olarak saptanan 141 lezyonun $102(\% 72,3)$ tanesinin jejuno-ileal alanda olduğu saptandı. 30

\section{Tablo 1. Semptom sayılarına göre hasta dağılımları}

\begin{tabular}{|c|c|c|c|c|c|}
\hline & Tek Semptom & İki Semptom & Üç Semptom & Dört Semptom & Beş Semptom \\
\hline Anemi & 21 & 19 & 7 & 2 & 0 \\
\hline Melena & 6 & 18 & 6 & 2 & 0 \\
\hline Ishal & 4 & 8 & 2 & 3 & 0 \\
\hline Karın ağrısı & 6 & 15 & 3 & 2 & 1 \\
\hline Hematokezya & 1 & 3 & 6 & 1 & 0 \\
\hline Geçirilmiş operasyon & 0 & 6 & 1 & 1 & 0 \\
\hline Şişkinlik & 0 & 4 & 3 & 0 & 1 \\
\hline Dispepsi & 0 & 4 & 0 & 0 & 0 \\
\hline Hematemez & 0 & 2 & 0 & 0 & 1 \\
\hline Ileus & 0 & 1 & 1 & 1 & 0 \\
\hline Kilo kaybı & 0 & 1 & 1 & 0 & 1 \\
\hline Bulantı-kusma & 0 & 1 & 0 & 0 & 1 \\
\hline Kabızlık & 0 & 1 & 0 & 0 & 0 \\
\hline GGK (+) & 0 & 1 & 0 & 0 & 0 \\
\hline PAF & 1 & 0 & 0 & 0 & 0 \\
\hline Toplam & 39 & 42 & 10 & 3 & 1 \\
\hline
\end{tabular}

GGK: Gaitada gizli kan, PAF: Perianal fistül 
hastada jejunal, 30 hastada ise ileal olmak üzere toplam 60 hastada jejuno-ileal lezyon mevcuttu. Hastaların 30'unda herhangi bir lezyon olmadığı saptandı. Kapsül endoskopi endikasyonlarına göre hasta dağılımı Tablo 2'de verilmiştir.

Hastalar geliş semptomları göz önüne alınarak en sık dört başvuru nedeni olan açılk GIS kanama, gizli GIS kanama, ishal ve karın ağrısı ana gruplarına alındı. Melena $(n=32)$ ve hematokezya $(\mathrm{n}=11)$ şikayetleri olup açık GIS kanaması grubuna dahil edilen hastalarda -ki bunların bazllarında birden fazla semptom mevcuttu- toplamda 56 lezyon saptanmış olup bunların \%42,9'u jejunum, \%23,2'si ileumdan kaynaklanmakta idi. Gizli GIS kanaması ile başvuran hastalarda 44 lezyon saptanmış olup \%61,4 ile en yüksek oranda jejunum gelmekte bunu \%29,5 ile ileum takip etmekte idi. Ishal şikayeti ile başvuran hastalarda-ki bunların bazılarında birden fazla semptom mevcuttu-16 lezyon saptanmış olup bunların \%50'si ileumda yer almaktaydı. Karın ağrısı semptomu ile gelen hastalarda -ki bunların bazılarında birden fazla semptom mevcuttu- 25 lezyon saptanmış olup bunların \%56'sı ileumda saptand. Açık ve gizli gastrointestinal sistem kanaması semptomu bulunan hastalarda en sik saptanan lezyon türü ve yeri jejunal angiodisplaziler olup sirasiyla 21/37 ve 20/32 olarak saptandı. Ishal ve karın ağrısı şikayetleri bulunan hastalarda en sık saptanan lezyon türü ve yeri ileal Crohn hastalı̆ğ olup sırasıyla 4/5 ve 3/4 olarak saptandı (Tablo 3-6).

Semptomlara göre dağılımlar incelendiğinde ise; başvurusu esnasında anemisi olan hasta sayıs 49 olup bunların \%79,6'sında herhangi bir lezyon saptanmıştır. Herhangi bir lezyon saptananların \%97,4'ünde ise bunun açılayıcı lezyon olduğu gözlenmiştir. Anemi şikayeti için açıklayıcı lezyon saptamada duyarllık \%97,44; özgüllük \%100; pozitif kestirim değeri \%100; negatif kestirim değeri \%90,91 ve doğruluk \%97,96 olarak saptanmıştır.

Melena ile gelen hastaları \%75'inde herhangi bir lezyon saptanmıştır. Herhangi bir lezyon saptananların \%91,7'sinde ise bunun açıklayıcı lezyon olduğu gözlenmiştir. Melana şikayetinde açıklayıcı lezyon saptamada duyarlılık \%91,67; özgüllük \%100; pozitif kestirim değeri \%100; negatif kestirim değeri \%80,00 ve doğruluk \%93,75 olarak saptanmıștır.

Karın ağrısı ile başvuran 27 olgunun \%70,4'ünde herhangi bir lezyon saptanmıştır. Herhangi bir lezyon saptananların \%78,9'unda ise bunun açılayıcı lezyon olduğu görülmektedir. Karın ağrısı şikayetinde açıklayııı lezyon saptamada

Tablo 2. Kapsül endoskopi endikasyonlarına göre hasta dağllımı

$\begin{array}{lccccccc} & \text { Semptom Sayısı } & \text { Lezyon Sayısı } & \text { Mide } & \text { Duodenum } & \text { Jejunum } & \text { İleum } & \text { Colon } \\ \text { Gizli GIS kanama } & 21 & 44 & 2 & 1 & 27 & 13 & 1 \\ \text { *Açık GIS kanama } & 43 & 56 & 11 & 2 & 24 & 13 & 6 \\ \text { *Ishal } & 17 & 16 & 1 & 2 & 2 & 8 & 3 \\ \text { *Karın ağrısı } & 27 & 25 & 6 & 2 & 1 & 14 & 2 \\ \text { **Toplam } & 108 & 141 & 20 & 7 & 54 & 48 & 12\end{array}$

Gastrointestinal sistem, ${ }^{*}$ Hastalarda birden fazla bildirilen şikayeti olanlar mevcuttur. ${ }^{* *}$ Nadir tanılar tablo dışı bırakılmıştır

Tablo 3. Açık GíS kanama ile gelen olguların dağılımı

\begin{tabular}{|c|c|c|c|c|c|c|}
\hline Patoloji & Lezyon Sayısı & Mide & Duodenum & Jejunum & İleum & Colon \\
\hline Anjiodisplazi & 37 & 4 & 0 & 21 & 8 & 4 \\
\hline Polip & 4 & 3 & 0 & 1 & 0 & 0 \\
\hline Gastrit & 2 & 2 & 0 & 0 & 0 & 0 \\
\hline Polipozis & 3 & 0 & 0 & 1 & 0 & 2 \\
\hline Crohn & 2 & 0 & 0 & 0 & 2 & 0 \\
\hline Dismotilite & 1 & 1 & 0 & 0 & 0 & 0 \\
\hline Ülser & 4 & 1 & 1 & 1 & 1 & 0 \\
\hline Çölyak & 1 & 0 & 1 & 0 & 0 & 0 \\
\hline Ileit & 1 & 0 & 0 & 0 & 1 & 0 \\
\hline GIST & 1 & 0 & 0 & 0 & 1 & 0 \\
\hline Toplam & 56 & 11 & 2 & 24 & 13 & 6 \\
\hline
\end{tabular}

GIST: Gastrointestinal stromal tümör 


$\begin{array}{lcccccc}\text { Tablo 4. Gizli Gís kanama ile gelen olguların dağlımı } & & & \\ \text { Patoloji } & \text { Lezyon Sayıs } & \text { Mide } & \text { Duodenum } & \text { Jejunum } & \text { Ileum } & \text { Colon } \\ \text { Anjiodisplazi } & 32 & 1 & 0 & 20 & 11 & 0 \\ \text { Polip } & 4 & 1 & 0 & 3 & 0 & 0 \\ \text { Hemanjiom } & 3 & 0 & 0 & 3 & 0 & 0 \\ \text { Polipozis } & 1 & 0 & 0 & 1 & 0 & 0 \\ \text { Crohn } & 1 & 0 & 0 & 0 & 1 & 0 \\ \text { Çölyak } & 1 & 0 & 1 & 0 & 0 & 0 \\ \text { lleit } & 1 & 0 & 0 & 0 & 1 & 0 \\ \text { Divertikülozis } & 1 & 0 & 0 & 0 & 0 & 1 \\ \text { Toplam } & 44 & 2 & 1 & 27 & 13 & 1\end{array}$

\section{Tablo 5. İshal ile gelen olguların dağılımı}

$\begin{array}{lcccccc}\text { Patoloji } & \text { Lezyon Sayısı } & \text { Mide } & \text { Duodenum } & \text { Jejunum } & \text { Ileum } & \text { Colon } \\ \text { Crohn } & 5 & 0 & 0 & 0 & 4 & 1 \\ \text { Anjiodisplazi } & 3 & 0 & 0 & 2 & 1 & 0 \\ \text { Polipozis } & 2 & 0 & 0 & 0 & 0 & 2 \\ \text { Çölyak } & 2 & 0 & 2 & 0 & 0 & 0 \\ \text { Iskemi } & 1 & 0 & 0 & 0 & 1 & 0 \\ \text { Dismotilite } & 1 & 1 & 0 & 0 & 0 & 0 \\ \text { Ülser } & 1 & 0 & 0 & 0 & 1 & 0 \\ \text { Striktür } & 1 & 0 & 0 & 0 & 1 & 0 \\ \text { Toplam } & 16 & 1 & 2 & 2 & 8 & 3\end{array}$

\section{Tablo 6. Karın ağrısı ile gelen olguların dağılımı}

$\begin{array}{lcccccc}\text { Patoloji } & \text { Lezyon Sayıs } & \text { Mide } & \text { Duodenum } & \text { Jejunum } & \text { Ileum } & \text { Colon } \\ \text { Crohn } & 4 & 0 & 0 & 0 & 3 & 1 \\ \text { Anjiodisplazi } & 4 & 1 & 0 & 1 & 2 & 0 \\ \text { Polipozis } & 1 & 0 & 0 & 0 & 0 & 1 \\ \text { Çölyak } & 2 & 0 & 2 & 0 & 0 & 0 \\ \text { Iskemi } & 1 & 0 & 0 & 0 & 1 & 0 \\ \text { Dismotilite } & 2 & 2 & 0 & 0 & 0 & 0 \\ \text { Ülser } & 1 & 0 & 0 & 0 & 1 & 0 \\ \text { Striktür } & 2 & 0 & 0 & 0 & 2 & 0 \\ \text { Polip } & 1 & 0 & 0 & 0 & 1 & 0 \\ \text { Gastrit } & 3 & 3 & 0 & 0 & 0 & 0 \\ \text { Ileit } & 3 & 0 & 0 & 0 & 3 & 0 \\ \text { Radyasyon enteriti } & 1 & 0 & 2 & 0 & 1 & 0 \\ \text { Toplam } & 25 & 6 & & 1 & 14 & 2\end{array}$

duyarllık \%78,95; özgüllük \%100; pozitif kestirim değeri \%100; negatif kestirim değeri \%66,67 ve doğruluk \%85,19 olarak saptanmıştır.
Ishal şikayeti ile başvuran 17 olgunun \%64,7'sinde herhangi bir lezyon saptanmıştır. Herhangi bir lezyon saptananların \%90,9'unda ise bunun açıklayıcı lezyon olduğu görülmekte- 


\section{Tablo 7. Semptomlar tek tek ele alındığında olgularda lezyon saptanması dağılımları}

\begin{tabular}{|c|c|c|c|c|c|}
\hline Tek Semptom* & $\begin{array}{l}\text { Semptom } \\
\text { Sayısı }\end{array}$ & $\begin{array}{l}\text { Herhangi } \\
\text { Lezyon (+) }\end{array}$ & $\begin{array}{l}\text { Herhangi } \\
\text { Lezyon (-) }\end{array}$ & $\begin{array}{l}\text { Açılayııı } \\
\text { Lezyon (+) }\end{array}$ & $\begin{array}{l}\text { Açılaayıcı } \\
\text { Lezyon (-) }\end{array}$ \\
\hline Anemi & 49 & $39(79,6)$ & $10(20,4)$ & $38(97,4)$ & $1(2,6)$ \\
\hline Melena & 32 & $24(75)$ & $8(25)$ & $22(91,7)$ & $2(8,3)$ \\
\hline Karın ağrısı & 27 & $19(70,4)$ & $8(29,6)$ & $15(78,9)$ & $4(21,1)$ \\
\hline İshal & 17 & $11(64,7)$ & $6(35,3)$ & $10(90,9)$ & $1(9,1)$ \\
\hline Hematokezya & 11 & $8(72,7)$ & $3(27,3)$ & $5(62,5)$ & $3(37,5)$ \\
\hline Geçirilmiş operasyon & 8 & $5(62,5)$ & $3(37,5)$ & $4(80)$ & $1(20)$ \\
\hline Şişkinlik & 8 & $7(87,5)$ & $1(12,5)$ & $6(85,7)$ & $1(14,3)$ \\
\hline Dispepsi & 4 & $2(50)$ & $2(50)$ & $1(50)$ & $1(50)$ \\
\hline Hematemez & 3 & $1(33,3)$ & $2(66,7)$ & $0(0)$ & $1(100)$ \\
\hline Ileus & 3 & $1(33,3)$ & $2(66,7)$ & $1(100)$ & $0(0)$ \\
\hline Kilo kaybı & 3 & $3(100)$ & $0(0)$ & $2(66,7)$ & $1(33,3)$ \\
\hline Bulantı-kusma & 2 & $1(50)$ & $1(50)$ & $1(100)$ & $0(0)$ \\
\hline Kabızlık & 1 & $0(0)$ & $1(100)$ & $0(0)$ & $0(0)$ \\
\hline GGK (+) & 1 & $1(100)$ & $0(0)$ & $1(100)$ & $0(0)$ \\
\hline PAF & 1 & $0(0)$ & $1(100)$ & $0(0)$ & $0(0)$ \\
\hline Toplam & 170 & $122(71,8)$ & $48(28,2)$ & $106(86,9)$ & $16(13,1)$ \\
\hline
\end{tabular}

*Birden fazla başvuru şikayeti mevcuttur. GGK: Gaitada gizli kan, PAF: Perianal fistül, (\%)

Tablo 8. Semptomlara göre açıklayıcı lezyon saptamada tanı tarama testleri sonuçları

$\begin{array}{lcccc}\text { Tek Semptom } & \text { Duyarlılık } & \text { Pozitif Kestirim Değeri } & \text { Negatif Kestirim Değeri } & \text { Doğruluk } \\ \text { Anemi } & 97,44 & 100,00 & 90,91 & 97,96 \\ \text { Melena } & 91,67 & 100,00 & 80,00 & 93,75 \\ \text { Karın ağrısı } & 78,95 & 100,00 & 66,67 & 85,19 \\ \text { Ishal } & 90,91 & 100,00 & 85,71 & 94,12 \\ \text { Hematokezya } & 62,50 & 100,00 & 50,00 & 72,73 \\ \text { Geçirilmiş operasyon } & 80,00 & 100,00 & 75,00 & 87,50 \\ \text { Şişkinlik } & 85,71 & 100,00 & 75,00 & 90,00 \\ \text { Dispepsi } & 50,00 & 100,00 & 66,67 & 75,00 \\ \text { Hematemez } & 0,00 & - & 66,67 & 66,67 \\ \text { Ileus } & 100,00 & 100,00 & 100,00 & 100,00 \\ \text { Kilo kaybı } & 66,67 & 100,00 & 0,00 & 66,67 \\ \text { Bulantı-kusma } & 100,00 & 100,00 & 100,00 & 100,00 \\ \text { Kabızlık } & - & - & 100,00 & 100,00 \\ \text { GGK (+) } & 100,00 & 100,00 & - & 100,00 \\ \text { PAF } & - & - & 100,00 & 100,00 \\ \text { Toplam } & 86,89 & 100,00 & 75,00 & 90,59\end{array}$

Hesaplanamayan değerler tabloda (-) şeklinde ifade edilmiştir. GGK: Gaitada gizli kan, PAF: Perianal fistül

dir. İshal şikayetinde açıklayıı lezyon saptamada duyarllık $\% 90,91$; özgüllük \%100; pozitif kestirim değeri \%100; negatif kestirim değeri \%85,71 ve doğruluk \%94,12'dir.
Hematokezya şikayeti ile başvuran hastaların \%72,7'sinde herhangi bir lezyon saptanmıştır. Herhangi bir lezyon saptananların \%62,5'inde ise bunun açılklayıcı lezyon olduğu 
görülmektedir. Hematokezya şikayetinde açılayıcı lezyon saptamada duyarllık \%62,50; özgüllük \%100; pozitif kestirim değeri \%100; negatif kestirim değeri \%50 ve doğruluk $\% 72,73$ 'dir.

Tüm semptomlar ele alındığında olguların \%71,8'inde herhangi bir lezyon saptanmıştır. Herhangi bir lezyon saptanan olguların \% 76,9'unda ise bunun açılkayıcı lezyon olduğu görülmektedir. Kapsül endoskopi yapılan hastalarımızda semptomlara neden olan sebebi açılayan lezyonları saptamada duyarllılı \%86,89; özgüllük \%100; pozitif kestirim değeri $\% 100$; negatif kestirim değeri \%75 ve doğruluk \%90,59 olarak saptandı (Tablo 7,8).
Hastaların 52'sinde birden fazla semptom olduğu gözlenmiştir. Şikayetler çoklu ele alındığında 15 olguda anemiye melenanın eşlik ettiği durum en sık tablo olarak karşımıza çıkmaktadır. Bu semptom birlikteliğinde herhangi bir lezyon saptanma olasıllı̆ı \%80 bulunmuş ve tüm bulunan lezyonların durumu açıklayıcı lezyon olduğu saptanmıştır (Tablo 9).

\section{TARTISQMA}

Alt ve üst GIS endoskopisi yapıldığı halde devam eden veya tekrarlayan kanamalara belirsiz gastrointestinal kanama (BGK) denir (11). DEA veya gaitada gizli kan (GGK) pozitifliği ile saptanan kanamalara gizli BGK, melena veya hemato-

Tablo 9. Semptomlar çoklu ele alındığında olgularda lezyon saptanması dağılımları

\begin{tabular}{|c|c|c|c|c|c|}
\hline Çoklu Semptom & $\begin{array}{l}\text { Semptom } \\
\text { Sayisı }\end{array}$ & $\begin{array}{l}\text { Herhangi } \\
\text { Lezyon }(+)\end{array}$ & $\begin{array}{l}\text { Herhangi } \\
\text { Lezyon (-) }\end{array}$ & $\begin{array}{l}\text { Açıklayıcı } \\
\text { Lezyon (+) }\end{array}$ & $\begin{array}{l}\text { Açıklayıcı } \\
\text { Lezyon (-) }\end{array}$ \\
\hline Anemi+Melena & 15 & $12(80)$ & $3(20)$ & $12(100)$ & 0 \\
\hline Anemi+Melena+Hematokezya & 6 & $5(83,3)$ & $1(16,7)$ & $5(100)$ & 0 \\
\hline İshal+Karın ağrısı & 7 & $3(42,9)$ & $4(57,1)$ & $3(100)$ & 0 \\
\hline Anemi+GGK (+) & 1 & $1(100)$ & 0 & $1(100)$ & 0 \\
\hline Anemi+Kilo kaybı & 1 & $1(100)$ & 0 & $1(100)$ & 0 \\
\hline Anemi+Karın ağrısı & 1 & $1(100)$ & 0 & $1(100)$ & 0 \\
\hline Anemi+Geçirilmiş operasyon & 1 & $1(100)$ & 0 & $1(100)$ & 0 \\
\hline Anemi+Geçirilmiş operasyon+Ileus & 1 & 0 & $1(100)$ & 0 & 0 \\
\hline Anemi+Melena+Hematokezya+ Ishal & 1 & $1(100)$ & 0 & $1(100)$ & 0 \\
\hline Anemi+Melena+Karın ağrısı+İshal & 1 & $1(100)$ & 0 & $1(100)$ & 0 \\
\hline $\begin{array}{l}\text { İshal+Karın ağrısı+Ileus+ } \\
\text { Geçirilmiş operasyon }\end{array}$ & 1 & $1(100)$ & 0 & $1(100)$ & 0 \\
\hline İshal+Karın ağrısı+Şişkinlik & 2 & $2(100)$ & 0 & $2(100)$ & 0 \\
\hline Karın ağrısı+Şişkinlik & 2 & $2(100)$ & 0 & $1(50)$ & $1(50)$ \\
\hline Karın ağrısı+Şişkinlik+Kilo kaybı & 1 & $1(100)$ & 0 & $1(100)$ & 0 \\
\hline Karın ağrısı+Bulantı & 1 & 0 & $1(100)$ & 0 & 0 \\
\hline Karın ağrısı+Geçirilmiş operasyon & 2 & $2(100)$ & 0 & $2(100)$ & 0 \\
\hline Karın ağrısı+Dispepsi & 2 & $2(100)$ & 0 & $1(50)$ & $1(50)$ \\
\hline Hematokezya+Melena & 1 & $1(100)$ & 0 & $1(100)$ & 0 \\
\hline İleus+Geçirilmiş operasyon & 1 & 0 & $1(100)$ & 0 & 0 \\
\hline İshal+Melena & 1 & $1(100)$ & 0 & $1(100)$ & 0 \\
\hline Geçirilmiş operasyon+Şişkinlik & 1 & $1(100)$ & 0 & $1(100)$ & 0 \\
\hline Şişkinlik+ Dispepsi & 1 & 0 & $1(100)$ & 0 & 0 \\
\hline Hematemez+Melena & 1 & 0 & $1(100)$ & 0 & 0 \\
\hline $\begin{array}{l}\text { Bulantı+ Karın ağrısı+ } \\
\text { Hematemez+ Şişkinlik+ Kilo kaybı }\end{array}$ & 1 & 0 & $1(100)$ & 0 & 0 \\
\hline Hematoçezya+ Dispepsi & 1 & 0 & $1(100)$ & 0 & 0 \\
\hline Hematoçezya+ Kabızlık & 1 & $1(100)$ & 0 & $1(100)$ & 0 \\
\hline Toplam & 55 & $40(72,7)$ & $15(27,3)$ & $38(95,0)$ & $2(5,0)$ \\
\hline
\end{tabular}

GGK: Gaitada gizli kan 
kezya ile saptanan kanamalara ise açık BGK denir (12). Kapsül endoskopideki gelişmeler BGK'ların nedenini saptamada etkin rol oynamaya başlamıştır (13). Kapsül endoskopiye sıklıkla gastroskopi ve kolonoskopi gibi geleneksel endoskopik tanı yöntemlerince kaynağı bulunamayan kanamaların saptanmasında başvurulmaktadır (14). Pek çok merkez enteroskopiyi BGK'sı olan hastalara geleneksel GIS endoskopileri sonrası bilgisayarlı tomografi (BT) ve KE yaptıktan sonra tercih etmektedir (15). Kapsül endoskopinin gizli BGK'ında tanısal faydası $\% 72,5$, açı BGK'larında ise \% 72,9 olarak saptanmıştır (16). Kapsül endoskopi BGK'ların nedeninin saptanmasinda enteroskopi, baryumlu grafi, BT ve magnetik rezonans (MR) görüntülemeye oranla daha üstün olduğu kabul edilmektedir (17-19). Belirsiz gastrointestinal kanamaların tanısı ve tedavisi sonrası olası tekrarlama riskinin değerlendirilmesinde de KE önemli yere sahiptir (20).

Hastalarımızın \%71,8'inde herhangi bir lezyon saptanmıştır. Herhangi bir lezyon saptanan olguların \%76,9'unda ise bunun şikayeti açıklayıcı lezyon olduğu görülmektedir. Tek semptom ile gelen olgularda açıklayııı lezyon saptama için; duyarlılık \%86.89; özgüllük \%100; pozitif kestirim değeri $\% 100$; negatif kestirim değeri \%75 ve doğruluk \%90,59 olarak saptanmıştır.

Ince barsak kanamaları tüm GIS kanamaların \%5'ini oluşturmaktadır. Bu kanamaların en sık sebebini anjioektaziler (\%50), kalanını ise inflamatuvar hastalıklar $(\% 26,8)$ ve tümörler $(\% 8,8)$ oluşturmaktadır (21). Erkeklerin ve menapoz sonrası kadınların \%2-5'inde DEA gözlenmektedir. Bu hastaların \%30'unda belirli bir neden bulunamamaktadır. Yaşlı hasta grubunda DEA'nin en sik nedeni tekrarlayan ve belirsiz gastrointestinal sistem kanamalarıdır. Bu durum alt ve üst GIS'in araştırılmasını zorunlu kılmaktadır (22-24). Buna rağmen hastaların sadece \%25'inde DEA'nin nedeni bulunabilmektedir (25). Özellikle yaşlı hasta grubunda tekrarlayan belirsiz gastrointestinal kanamaların olduğu bilinmektedir. $\mathrm{Bu}$ hasta grubu kullandıkları kanama arttırıcı ilaç tedavileri yüzünden inatçı ve devam eden açık BGK ve gizli BGK'na yatkın hale gelmektedir. Geleneksel endoskopilerinde herhangi bir neden saptanmayan hastalar ilaç tedavilerine devam etmekte ve bu da yanlış ve geciken tanı dolayısıyla ölümlere sebep olabilmektedir. Bu hasta grubunda KE ve gerekirse ısrarcı ikinci geleneksel endoskopilerden kaçınılmamalıdır (24,26). 227 çalışmayı içeren sistematik bir derlemede KE yapilan hastaların \%59,4' ünde DEA'nin nedeni belirlenebilmiştir (21). Diğer çalışmalarda KE'nin tanı koymadaki doğruluk oranının \%35-66,6 olduğu tespit edilmiştir $(27,28)$. Kapsül endoskopi BGK'nın değerlendirilmesinde enteroskopiye ve mezenter anjiografiye üstün saptanmıştır. Ince barsağın değerlendirilmesinde bilgisayarlı tomografi ile birlikte tamamlayıcı yöntemler olarak kabul edilmektedir. Özellikle enteroskopi yapılacak hastaların seçimi ve lezyon bulunan sahaya girişimin yapılabilmesi için kılavuz görevi üstlenebilmektedir (29). Bizim çalışmamızda gizli GIS kanaması ile gelen olgularda 44 lezyon saptanmış olup, bunların \%61,4'ü jejunumda, \%29,5’i ise ileumda gözlenmiştir. Açık GIS kanaması ile gelen olgularda 56 lezyon saptanmıs olup bunların $\% 42,9$ 'u jejunum, \%23,2'si ileum, \%19,6's1 mide, \%10,7'si kolon ve \%3,6'sı ise duodenumda saptanmıştır. Şikayetlere göre dağılımlar incelendiğinde; en yüksek düzeyde 49 hasta anemi ile başvurmuş ve bunların \%79,6'sında herhangi bir lezyon saptanmıștır. Herhangi bir lezyon saptanan olguların \%97,4'ünde ise bunun açılayııı lezyon olduğu görülmüştür. Anemide açıklayııı lezyon saptama için; duyarlılık \%97,44, özgüllük \%100, pozitif kestirim değeri \%100, negatif kestirim değeri \%90,91 ve doğruluk \%97,96 olarak saptanmıştır. Gizli GiS kanaması ile gelen hastalarda lezyonların \%61,4'ü jejunumda, \%29,5'i ise ileumda saptanmıştır. Hematokezya ile başvuran olguların \%72,7'sinde herhangi bir lezyon saptanmıştır. Herhangi bir lezyon saptananların \%62,5'inde ise bunun açıklayıcı lezyon olduğu görülmektedir. Hematokezya için açıklayıcı lezyon saptamada; duyarlılık \%62,50, özgüllük $\% 100$, pozitif kestirim değeri \%100, negatif kestirim değeri $\% 50,00$ ve doğruluk \%72,73 olarak bulunmuştur. Melena ile gelen hastaların \%75'inde herhangi bir lezyon saptanmıștır. Herhangi bir lezyon saptananların \%91,7'sinde ise bunun açıklayıcı lezyon olduğu görülmektedir. Melanada açıklayıcı lezyon saptama için; duyarlılık \%91,67, özgüllük \%100, pozitif kestirim değeri \%100, negatif kestirim değeri \%80,00 ve doğruluk \%93,75 olarak saptanmıştır. Hematemez'de açıklayıcı lezyon saptama için; duyarlılık \%0; özgüllük \%100, negatif kestirim değeri \%66,67 ve doğruluk \% 66.67 olarak saptanmıştır.

Uluslararası kılavuzlar Crohn hastalığı şüphesi olan hastalarda geleneksel ileokolonoskopi bulgularına bakılmaksızın ince barsak görüntülenmesini önermektedir. Kapsül endoskopi t1kayıcı durum olmadığında bu tür hastalara ilk uygulanacak yöntem olarak belirtilmektedir (30). Her ne kadar MR enterografi ve ultrasonografi (USG) geliştikçe transmural barsak enflamasyonu bir miktar değerlendirilebilse de yüzeysel mukozal lezyonların değerlendirilmesinde yetersiz kalmaktadır$\operatorname{lar}(31,32)$.

Günümüzde kolon kapsül endoskopisi de kullanılmaya başlanmıştır. Özellikle tamamlanamamıs kolonoskopi ve kolonoskopiye direnen hastalarda tatminkar sonuçlar elde edilmektedir $(33,34)$. Geleneksel kolonoskopide kanama, perforasyon gibi ciddi komplikasyonların, yan etkilerin, hasta direnci ve anestezi gereksiniminin olabileceği bilinmektedir (35). Bu da kolorektal kanser taramalarında istenenin altında toplum taraması oranlarına neden olmaktadır (36). Şu durumda hastaların arzusu ve kayglları göz ardı edilemez. Her ne kadar BT kolonografi gibi yöntemler geleneksel kolonoskopiye alternatif olarak klinik uygulamaya alınmaya çalışıl- 
mışsa da hem doğru tanıdaki yetersizliği hem de mukozanın izlenememesi ciddi engel olarak karşımıza çıkmaktadır (37). Kolon KE'nin özellikle tarama programındaki hastalara rahatlık sağladığı ve geleneksel kolonoskopiye iyi bir alternatif olabileceği gözlenmiştir. Ancak yine de geleneksel kolonoskopiye tam olarak alternatif olabilmesi için teknolojik ilerlemelere gereksinim olduğu düşünülmektedir (38). Ince barsağa yönelik yapılan kapsül endoskopi sırasında çekuma kapsülün geçişi sonrası değerlendirilme kirlilik veya tam kolonik değerlendirme olamayacağı bilinse bile devam etmelidir. Bu esnada geleneksel kolonoskopi ile gözden kaçan lezyonların saptanabildiği gözlenmiştir (39). Bizim çalışmamızda daha önce saptanamamış 12/170 lezyonun kapsül endoskopi ile saptanmış olduğu gözlenmiştir. Bu 12 lezyonun açık GIS kanamalı hastalarda 4'ünün angiodisplazi, 2'sinin polipozis olduğu; karın ağrısı olanlarda ise l'inin divertikülozis, l'inin Crohn hastalığı, l'inin ise polipozis olduğu saptanmıştır.

Gaita hızında artış ve kıvamındaki azalışın dört haftadan uzun süreyle devam etmesine kronik ishal denir (40). Geçmişte karın ağrısında kapsül endoskopinin yeri tartışmalı iken günümüzde nedeni belirlenemeyen karın ağrılarının sebebini araştırmak için kullanılmaya başlanmasıyla hastaların \%23'ünde bir sebep belirlenebilmektedir (7). Aynı şekilde sebebi belirlenemeyen veya ince barsak kökenli ishallerin araştırılmasında da kapsül endoskopi artan oranlarda kullanılmaya başlanmıştır $(41,42)$. Song ve arkadaşlarının 91 hastayı içeren çalışmasında kronik ishalde KE'nin tanısal faydası \%42,9 olarak saptanmıştır. Kapsül endoskopi sonrası hastaların \%34,l'inde tanı değişmiş, tedavide değişikliğe gidilmiş ve kapsül endoskopi önerilmiştir (6). Çalışmamızda ishal ile başvuran hastalarda 16 lezyon saptanmış olup; bunların \%50'si ileum, \%18,8'i kolon, \%12,5'u ise jejunum ve duodenumda yer almaktaydı. Herhangi bir lezyon saptananların \%90,9'unda ise bunun açıklayıcı lezyon olduğu görülmektedir. Ishalde açıklayıcı lezyon saptama için; duyarlılık \%90,91, özgüllük \%100, pozitif kestirim değeri \%100, negatif kestirim değeri \%85,71 ve doğruluk \%94,12 olarak saptanmıştır.

Ince barsak tümörleri GIS tümörlerinin \%1-3'lük kısmını oluşturur (43). Ince barsak tümörlerinin tanısı çoğu zaman gecikir (44). Bu gecikmelerin önüne geçmek için özellikle genç erişkinlerde kaynağı belirsiz DEA'lerinin olduğu durumlarda kapsül endoskopi düşünülmelidir. Kapsül endoskopi özellikle geleneksel tanı yöntemlerinin etkisiz kaldığı durumlarda gerek ince barsak tümörlerinin tanısı gerekse tedavi yönetiminde paha biçilmez veriler sunabilmektedir (45). Bizim çalışmamızda açık GIS kanamalıların 4'ü polip l'i gastrointestinal stromal tümör (GIST), gizli GIS kanamalıların 3’ü hemangiom 4'ü polip, karın ağrısı ile gelenlerin ise 1 lezyonu polip olarak saptanmıştır.
Ek olarak KE; ilaçların GIS üzerindeki yan etkileri, gastrointestinal sistemin motor hastalıkları ve CH'nın tedaviye yanıtı ve dağllımının belirlenmesinde de yararlı bir tanı yöntemi olarak düşünülmeye başlanmış ve klinik uygulamada yerini almıştır $(46,47,8)$. Karın ağrısında lezyonlarının \%56'sı ileumda, \%24'ü midede görülmektedir. Karın ağrısı ile başvuran 27 olgunun \%70,4'ünde herhangi bir lezyon saptanmıştır. Herhangi bir lezyon saptananların \%78,9'unda ise bunun açıklayıcı lezyon olduğu görülmektedir. Karın ağrısı şikayetinde açılayıcı lezyon saptama için; duyarlılık \%78,95, özgüllük \%100, pozitif kestirim değeri \%100, negatif kestirim değeri \%66,67 ve doğruluk \%85,19 olarak gözlenmiştir. Bizim çalışmamızda açık GIS kanamasıyla başvuran hastaların l'i, ishal ile başvuranların l'i ve karın ağrısı ile başvuran hastaların 2'sinde dismotilite saptanmıştır.

Hastaların 39'unun sadece tek semptom ile geldiği gözlenmiştir. Tek semptom bağlamında ele alındığında semptoma göre kapsül endoskopinin etkinliğinde aşırı uç durumların olduğu gözlenmiştir. Ancak bu çalışmada tek semptomla gelen hastaların yanı sıra kalan tüm hastalarda çoklu semptomatoloji ile hastaların tarafımıza başvurduğunu belirtmek isteriz. Bu durum ele alındığında kapsül endoskopinin çoklu semptomatolojisi olan hasta grubunda daha etkin olduğu gözlemlenmiştir.

Çalışmamızda tüm mevcut şikayetlerle tarafımıza başvuran hastaların 27'sinde $(\% 28,4)$ kapsül endoskopiyle de herhangi bir lezyon saptamamıştır. Bu durum kapsül endoskopinin gastrointestinal semptomatolojideki gücünü sorgulamamıza neden olmakla birlikte çalışmamızın ilgisi dışındadır. Çalışmamızın amacı var olan semptoma göre kapsül endoskopinin gücünü sorgulamaktır. Şayet uygun endikasyon ve öncül işlem ve tetkiklere ağırlık verilirse kapsül endoskopinin sebepsiz yere yapılması engellenebilir. Böylece hem zaman hem de ekonomik kayıpların önüne geçilebileceği kanısındayız.

Günümüzdeki yeni gelişmeler ile kapsül endoskopi çağı daha da ilerlemeler kaydedeceğe benzemektedir. Özellikle hastaların evde rahatça uygulamasına elverişlilik, eş zamanlı görüntüleme, ağızdan anüse tüm GIS’in görüntülenmesi, daha kısa sürede kapsül endoskopinin okunabileceği patoloji bazlı uyarı sistemleri ve dışarıdan yönlendirmeye firsat sunacak manyetik kapsül endoskopi gibi uygulamalar üzerinde kapsamlı çalışmalar sürdürülmektedir (48).

Olgularda 141 lezyonunun 102'sinin (\%72,3) jejuno-ileal alanda saptanan lezyonlardan köken aldığı gözlenmiştir. Bu durum göz önüne alındığında refrakter veya kökeni belirsiz semptomları olan ve uygun endikasyonlu hastalarda geleneksel endoskopi ile tanı konamayan durumlarda kapsül endoskopinin son derece önemli ve kurtarıcı olduğu anlaşılmaktadır. 


\section{KAYNAKLAR}

1. Lewis BS, Swain P. Capsule endoscopy in the evaluation of patients with suspected small intestinal bleeding: Results of a pilot study. Gastrointest Endosc 2002;56:349-53.

2. ASGE Technology Committee, Chauhan SS, Manfredi MA, et al. Enteroscopy. Gastrointest Endosc 2015;82:975-90.

3. Matas JL, Asteinza M, Loscos JM, et al. Diagnostic yield and safety of capsule endoscopy. Rev Esp Enferm Dig 2006;98:666-73.

4. Pennazio M, Spada C, Eliakim R, et al. Small-bowel capsule endoscopy and device-assisted enteroscopy for diagnosis and treatment of small-bowel disorders: European Society of Gastrointestinal Endoscopy (ESGE) Clinical Guideline. Endoscopy 2015;47:352-76

5. Tacheci I, Devière J, Kopacova M, et al. The importance of upper gastrointestinal lesions detected with capsule endoscopy in patients with obscure digestive bleeding. Acta Gastroenterol Belg 2011;74:395-9.

6. Song HJ, Moon JS, Jeon SR, et al; Korean Gut Image Study Group. Diagnostic yield and clinical impact of video capsule endoscopy in patients with chronic diarrhea: A Korean multicenter CAPENTRY study. Gut Liver 2017;11:253-260

7. Yang L, Chen Y, Zhang B, et al. Increased diagnostic yield of capsule endoscopy in patients with chronic abdominal pain. PLoS One 2014;9:e87396

8. Malagelada C, De Iorio F, Azpiroz F, et al. New insight into intestinal motor function via noninvasive endoluminal image analysis. Gastroenterology 2008;135:1155-62.

9. Fry LC, Bellutti M, Neumann H, et al. Incidence of bleeding lesions within reach of conventional upper and lower endoscopes in patients undergoing double-balloon enteroscopy for obscure gastrointestinal bleeding. Aliment Pharmacol Ther 2009;29:342-9.

10. Schönfeld J, Hauser D, Hartmann CA, Schroeder J. Adenomas and carcinomas missed in routine colonoscopy: A prospective study in resected colon segments. Z Gastroenterol 2014;52:1153-6.

11. ASGE Standards of Practice Committee, Gurudu SR, Bruining DH, et al. The role of endoscopy in the management of suspected small-bowel bleeding. Gastrointest Endosc 2017;85:22-31.

12. Rondonotti E, Marmo R, Petracchini M, et al. The American Society for Gastrointestinal Endoscopy (ASGE) diagnostic algorithm for obscure gastrointestinal bleeding: eight burning questions from everyday clinical practice. Dig Liver Dis 2013;45:179-85

13. Iddan G, Meron G, Glukhovsky A, Swain P. Wireless capsule endoscopy. Nature 2000;405:417.

14. Martínez-González J, TéllezVillajos L, Aicart-Ramos M, et al. Capsule endoscopy and obscure gastrointestinal bleeding: Does the form of presentation matter? Gastroenterol Hepatol 2015;38:47-53.

15. Singh A, Marshall C, Chaudhuri B, et al. Timing of video capsule endoscopy relative to overt obscure GI bleeding: implications from a retrospective study. Gastrointest Endosc 2013;77: 761-6.

16. Law R, Varayil JE, Wong Kee Song LM, et al. Assessment of multi-modality evaluations of obscure gastrointestinal bleeding. World J Gastroenterol 2017;23:614-21.

17. Triester SL, Leighton JA, Leontiadis GI, et al. A meta-analysis of the yield of capsule endoscopy compared to other diagnostic modalities in patients with obscure gastrointestinal bleeding. Am J Gastroenterol 2005; 100:2407-18

18. Leighton JA, Triester SL, Sharma VK. Capsule endoscopy: a meta-analysis for use with obscure gastrointestinal bleeding and Crohn's disease. Gastrointest Endosc Clin N Am 2006;16:229-50.

19. Yung DE, Koulaouzidis A, Avni T, et al. Clinical outcomes of negative small-bowel capsule endoscopy for small-bowel bleeding: a systematic review and meta-analysis. Gastrointest Endosc 2017;85:305-17.

20. Tziatzios G, Gkolfakis P, Dimitriadis GD, Triantafyllou K. Long-term effects of video capsule endoscopy in the management of obscure gastrointestinal bleeding. Ann Transl Med 2017;5:196.

21. Liao Z, Gao R, Xu C, Li ZS. Indications and detection, completion, and retention rates of small-bowel capsule endoscopy: a systematic review. Gastrointest Endosc 2010;71:280-6.
22. Goddard AF, James MW, McIntyre AS, Scott BB; British Society of Gastroenterology. Guidelines for the management of iron deficiency anaemia. Gut 2011;60:1309-16.

23. Pang WW, Schrier SL. Anemia in the elderly. Curr Opin Hematol 2012;19:133-40

24. Ormeci A, Akyuz F, Baran B, et al. What is the impact of capsule endoscopy in the long term period? World J Gastrointest Endosc 2016 10;8:344-8.

25. Clark SF. Iron deficiency anemia: diagnosis and management. Curr Opin Gastroenterol 2009;25:122-8.

26. Clere-Jehl R, Sauleau E, Ciuca S, et al. Outcome of endoscopy-negative iron deficiency anemia in patients above 65: A longitudinal multicenter cohort. Medicine 2016;95:e5339.

27. Koulaouzidis A, Rondonotti E, Giannakou A, Plevris JN. Diagnostic yield of small-bowel capsule endoscopy in patients with iron-deficiency anemia: a systematic review. Gastrointest Endosc 2012; 76:983-92.

28. Sidhu PS, McAlindon ME, Drew K, et al. Diagnostic yield of small-bowel capsule endoscopy in patients with iron deficiency anemia: does it affect management? Gastrointest Endosc 2013;78:800-1.

29. Pasha SF, Leighton JA. Evidence-Based Guide on Capsule Endoscopy for Small Bowel Bleeding. Gastroenterol Hepatol 2017;13:88-93.

30. Jensen MD, Brodersen JB, Kjeldsen J. Capsule endoscopy for the diagnosis and follow up of Crohn's disease: a comprehensive review of current status. Ann Gastroenterol 2017:30:168-78.

31. Panes J, Bouhnik Y, Reinisch W, et al. Imaging techniques for assessment of inflammatory bowel disease: joint ECCO and ESGAR evidence-based consensus guidelines. J Crohns Colitis 2013;7:556-85.

32. Panés J, Bouzas R, Chaparro M, et al. Systematic review: the use of ultrasonography, computed tomography and magnetic resonance imaging for the diagnosis, assessment of activity and abdominal complications of Crohn's disease. Aliment Pharmacol Ther 2011;34:125-45.

33. Spada C, Hassan C, Barbaro B, et al. Colon capsule versus CT colonography in patients with incomplete colonoscopy: a prospective, comparative trial. Gut 2015:64:272-81.

34. Rondonotti E, Borghi C, Mandelli G, et al. Accuracy of capsule colonoscopy and computed tomographic colonography in individuals with positive results from the fecal occult blood test. Clin Gastroenterol Hepatol 2014;12:1303-10

35. ASGE Standards of Practice Committee, Fisher DA, Maple JT, et al. Complications of colonoscopy. Gastrointest Endosc 2011;74:745-52.

36. Bujanda L, Sarasqueta C, Zubiaurre L, et al. Low adherence to colonoscopy in the screening of first-degree relatives of patients with colorectal cancer. Gut 2007;56:1714-8.

37. IJspeert JE, TuteinNolthenius CJ, Kuipers EJ, et al. CT-Colonography vs. colonoscopy for detection of high-risk sessile serrated polyps. Am J Gastroenterol 2016;111:516-22

38. Toth E, Yung DE, Nemeth A, et al. Video capsule colonoscopy in routine clinical practice. Ann Transl Med 2017;5:195.

39. Juanmartiñena Fernández JF, Fernández-UriénSainz I, Zabalza Ollo B, et al. Colonic lesions in patients under going small bowel capsule endoscopy: incidence, diagnostic and therapeutic impact. Rev Esp Enferm Dig 2017;109.

40. Juckett G, Trivedi R. Evaluation of chronic diarrhea. Am Fam Physician 2011;84:1119-26

41. May A, Manner H, Schneider M, et al. Prospective multicenter trial of capsule endoscopy in patients with chronic abdominal pain, diarrhea and other signs and symptoms (CEDAP-Plus Study). Endoscopy 2007;39:606-12

42. Katsinelos P, Fasoulas K, Beltsis A, et al. Diagnostic yield and clinical impact of wireless capsule endoscopy in patients with chronic abdominal pain with or without diarrhea: a Greek multicenter study. Eur J Intern Med 2011;22:63-6.

43. Pan SY, Morrison H. Epidemiology of cancer of the small intestine. World J Gastrointest Oncol 2011;3:33-42. 
44. Pennazio M, Rondonotti E, de Franchis R. Capsule endoscopy in neoplastic diseases. World J Gastroenterol 2008;14:5245-53.

45. Johnston CA, Yung DE, Joshi A, et al. Small bowel malignancy in patients undergoing capsule endoscopy at a tertiary care academic center: Case series and review of the literature. Endosc Int Open 2017;5:E46370.

46. Graham DY, Opekun AR, Willingham FF, Qureshi WA. Visible small intestinal mucosal injury in chronic NSAID users. Clin Gastroenterol Hepatol 2005;3:55-9.
47. Kopylov U, Yablecovitch D, Lahat A, et al. Detection of small bowel mucosal healing and deep remission in patients with known small bowel Crohn's disease using biomarkers, capsule endoscopy and imaging. Am J Gastroenterol 2015;110:1316-23.

48. Eliakim R. Where do I see minimally invasive endoscopy in 2020: clock is ticking. Ann Transl Med 2017;5:202. 